\title{
Internet of Things Based Smart Agricultural System for Farmers
}

\author{
Raja Venkatesh Gurugubelli ${ }^{1}$, Dilleswararao Nettimi ${ }^{1}$, Vidya Sagar Gorle ${ }^{1}$, Sairam Panda ${ }^{1}$, \\ Anil Kumar Navuluri ${ }^{1}$, Rosepreet Kaur Bhogal ${ }^{2}$ \\ ${ }^{1}$ Lovely Professional University Phagwara, India \\ ${ }^{2}$ Assistant Professor, Lovely Professional University Phagwara, India
}

\begin{abstract}
Article Info

Volume 7, Issue 3

Page Number: 535-540

Publication Issue :

May-June-2021

\section{Article History}

Accepted : 20 June 2021

Published : 25 June 2021

The Internet of Things (IoT) is the present and future of every industry, shaping everyone's life by speeding up everything. It's a set of standalone devices that power a self-configuring network. The latest developments in Smart Farming with the help of IoT are slowly but steadily spinning the features of traditional agriculture procedures by not only making it an option, but also by lowering the cost for farmers and decreasing the time it takes to harvest. The aim is to offer a technology that can send messages to farmers through various programmers. Farmers will benefit from the results because they will be able to collect data from the field in real time (temperature, humidity, soil moisture, UV index, and IR) and use it to start doing smart farming by growing crop yields and conserving water. The study presented in this paper makes use of the ESP32 Node MCU, DHT11, and Soil Moisture Sensor, GSM Module, and live data feed can be monitored on Things of Speak an IoT platform. This will have allowed farmers to control their plants in accordance with modern farming methods. [1] Keywords : ESP32s, DHT11 Temperature and Humidity Sensor, Soil Moisture Module (SI1145), Digital UV Index, GSM Module, Relay, IR sensors.
\end{abstract}

\section{INTRODUCTION}

Internet of Things (IoT) is a network of interconnected sharp computers that are capable of interacting with one another and producing precise data about the situations under which they function. Thus, in the context of IoT, every computer which capable of establishing a connection to the Internet, such as household equipment, electronics, agricultural, or industrial machinery, may be called a "item."
Despite the detail that the concept of the Internet of Things is not new, it has grown in popularity in recent years, owing to the advancement of technologies that support it, such as the upgrading of hardware with the resulting reduction in size and power usage, the upgrade of networking with the Internet and between components through wireless connections, cloud computing, artificial intelligence, and big data. All of these scientific elements work together to create a network of sensors that can share data and knowledge and work actively based

Copyright: @ the author(s), publisher and licensee Technoscience Academy. This is an open-access article distributed under the terms of the Creative Commons Attribution Non-Commercial License, which permits unrestricted non-commercial use, distribution, and reproduction in any medium, provided the original work is properly cited 
on network inputs. According to, the architecture of IoT systems is similar to that of other computer systems, but it must take into understanding the paradigm's unique features, such as applications, detection and control of remote components, processing functions and recognition. Agriculture is the groundwork of human civilization since it is the primary source of food grains and other raw materials. It is vital to the growth of the country's income. It also provides people with a sufficient number of job opportunities.

The agriculture sector must develop in order for the country's economy to improve. Unfortunately, many farmers continue to practise old farming practises, which result in low crop yields and. However, wherever IoT automation was used and humans were replaced by digital computers, the yield was higher. Agriculture-related issues have always been a hindrance to the country's growth. Smart agriculture, which involves modernizing current agricultural practices, is the only solution to this issue. The proposed framework is useful for tracking field data as well as managing field activities, and it offers versatility. The aim of the project is to make agriculture more efficient and productive by using automation and Internet of Things (IoT) technologies. [2]

\section{A. Monitoring}

Sensors are placed along the farms to detect variations in sun, precipitation, temperature, moisture, and soil acidity. Every animal or person observed by the infrared sensors is analyzed, and the farmer is alerted. As a result, distant sensing can help to deter disease spread and monitor crop development. [2]

\section{B. Climate changes}

Sensor data on humidity, temperature, precipitation, and dew identification aids in deciding the climate trend in farms such that appropriate crops can be cultivated at specific times. [2]

\section{PROPOSED SYSTEM}

Our project's goal is to begin smart agriculture, which entails reducing manpower and addressing issues in cropping and some agriculture farms. And, thanks to the internet of things, the data is sent immediately to the appropriate location (IoT). The project employs a Node MCU, as well as a Wi-Fi module capable of linking to a network.

\section{A. Data from the Climate}

As soil moisture sensor detects moisture from the soil, and the moisture content of the soil is determined in a proportion The humidity and temperature are measured in percentage and Celsius, respectively by the DHT22 Humidity and Temperature Sensor. The light intensity is determined in candela by a light sensor.

A rain sensor in millimetres determines the rain level.

\section{B. Micro-controller}

It is the components of the planned system's Microcontroller assembly. This Micro-controller assembly is the system's hardware, and it controls data acquisition through the sensors it contains. The microcontroller's function is to connect with cloud servers, and it has an embedded Wi-Fi module with a range of up to 300 meters, which aids in information propagation across the network.

\section{B. Cloud}

Storage the network is in charge of sending data to cloud storage, which analyses and performs calculations with sensor data obtained in raw form and displays it on the IoT interface. The network between the hardware components and the cloud can be built in one of two ways: via MQTT agents 
and the MQTT protocol, or via HTTP modules and the HTTP protocol. MQTT is favoured to HTTP because it is message-based, while HTTP is document-based, making MQTT more dependable. [12]

\section{IOT Interface}

IoT APIs are used to communicate with applications and IoT devices, and logical connectors are used to link them. APIs display data that allows certain machines to send data to the application, effectively serving as a data interface. They also allow the app to take control of the smartphone and serve as a user interface.

\section{B. Hand held Device}

The Data can be monitored using a web-based or smartphone device. These applications are run on cell phones that have an LCD or OLED display for displaying data.

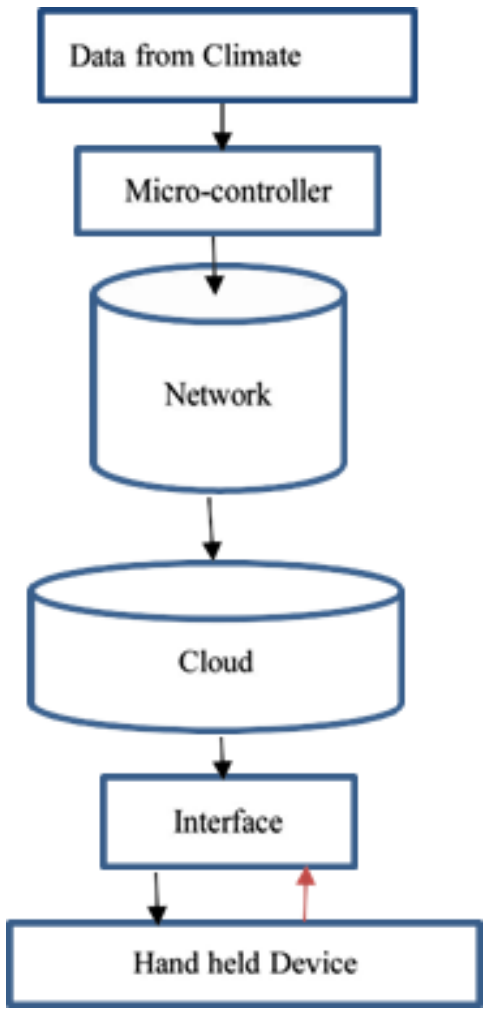

Fig.1(flow chart of Proposed System)

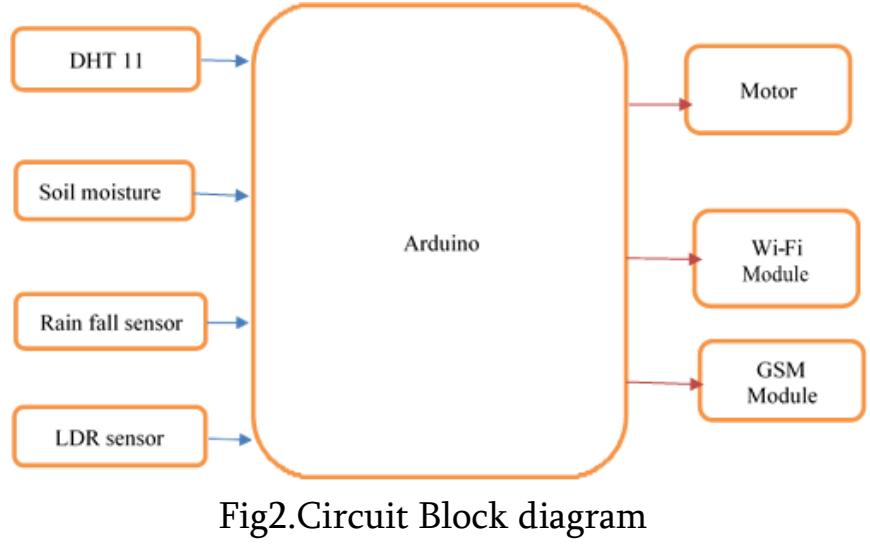

\section{III.EXPERIMENTAL WORK}

Implementation of IOT in the field: By 2050, the world's population is projected to reach ten billion people, posing a significant challenge for agriculture. Despite problems such as extreme weather, riots, climate change, and farming's environmental impact, the need for additional food must be addressed. Agriculture must adapt to modern technologies in order to fulfil these growing demands. New IoTenabled smart farming apps can help the agriculture industry reduce waste and increase productivity. It is the incorporation of emerging information and communication technologies (ICT) into agriculture. A device is designed for tracking the harvest area with the help of sensors in IoT-based smart farming (temperature, light, soil moisture, humidity etc.). Farmers can monitor field circumstances from any location. [9]

Implementation of Soil moisture Sensing part in smart irrigation: Water is a necessary and vital aspect of agriculture and farm development, as well as a critical component of our quality of life. Soil moisture sensors senses the water level of soil with high precision with rich index . Microwave radiation is influenced by soil moisture and is utilized in hydrology and irrigation for remote sensing. Farmers may use movable probe devices. Soil moisture sensors aid in efficient irrigation. Irrigation control that is done correctly produces 
healthier seeds, uses less inputs, and improves profitability. Soil moisture sensors help irrigators figure out what's going on in a crop's root zone. As a result, the amount of water used will be reduced. [6]

\section{IV.COMPONENTS}

NodeMCU: The ESP8266 is a small module that enables microcontrollers to link to a Wi-Fi network and establish basic TCP/IP connections using Hayesstyle commands. However, there was absolutely no English-language literature available at first for the chip and the commands it could accept [2]. Many hackers were drawn to the module, the chip, and the applications on it, as well as to translate the Chinese documents, because of the low price and the fact that there were few external components on the module, which meant that it could ultimately be very inexpensive in volume.

Arduino: A wide-ranging of microprocessors and Micro controllers are used in Arduino board designs. The boards have digital and analog input \& output (IO) pins that can be connected to various extension serial networks interfaces, including Universal Serial boards ('shields') or bread boards (for prototyping) as well as other circuits. The boards include serial communications interfaces, including Universal Serial Bus (USB) on some models, which are also utilized for loading programs. The micro-controllers can be programmed using the $\mathrm{C}$ and $\mathrm{C}++$ programming languages, using a standard Application Programmable Interface which is also known as the "Arduino language". In addition to using conventional compiler tool-chains, the Arduino provides an integrated development environment (IDE) and a command line tool (Arduino) developed in Go Language .[3]

GSM Module: A GSM Modem or Module is a hardware device that uses GSM mobile phone technology to provide a data-link to a Remotely Located network. From the viewpoint of the mobile telephone network technology, they are fundamentally identical to an common mobile phone, as well as the want for a SIM to find themselves to the network. GSM modems usually provide TTL- level serial interfaces to their host. They are typically utilized as element of an embedded systems.

Soil Moisture Module: This soil moisture sensor module is utilized to identify the moisture of the soil. It measures the volumetric content of water inside the soil and gives us the moisture level as output. The module has both Digital and Analog Data outs as $\mathrm{A} 0$ and D0 outputs and a potentiometer to adjust the limit the level.

Relay Module: An electromagnet operates a power relay module, which is an electronic switch. A separate low-power pulse from a microcontroller activates the electromagnet. The electromagnet pulls to open or close an electrical circuit when triggered. Water pump Module: With a $12 \mathrm{~V}$ power supply, the DC Water Pump module is very common. It's a completely submersible water pump with a variety of uses, including water, soda drink, project job, and scientific model applications.

DHT11: The DHT11 is a simple digital temperature and humidity sensor with a low price tag. It measures the ambient air with a capacitive humidity sensor and a thermistor and outputs a digital signal on the data pin (no analogue input pins needed). It's easy to use, but data collection necessitates careful scheduling. The only major drawback of this sensor is $t$ you are able to only get new data from it for every 2 seconds, so sensor interpretations can be up to 2 seconds old while using our library. 
Rain sensor module: Raindrop Sensor is a tool used for sensing rain. It comprises of two Sub Modules, a rain board that detects the rain and a control module, which compares the analog value, and converts it to a digital value. [5]

PH sensor: A pH sensor assists to compute the acidity or alkalinity of the water with a value between $0-14$. When the $\mathrm{pH}$ value dips below seven, the water starts to become more acidic. Any number above seven equates to more alkaline. Each type of $\mathrm{pH}$ sensor works differently to measure the quality of the water. [9]

LDR sensor: Photo resistors, also seen as light dependent resistors (LDR), are light sensitive devices most frequently used to gives the presence or absence of light, or to measure the light intensity. LDRs have a sensitivity that varies with the wavelength of the light applied and are nonlinear devices.

\section{CONCLUSION}

Smart Agriculture is a device that reduces the amount of time and resources used to execute a task physically. The Internet of Things infrastructure is regulated by this device. Water is a valuable resource and can be used wisely. Agriculture is one of the most water-intensive industries. Irrigation of the field is a time-consuming process that should be completed on a regular basis. An auto irrigation structure that calculates moisture content, humidity, temperature, rain observation, and water level is the subject of this mission. The leftover water is then harvested from the cultivation field and returned to the tank. When there is a person or animal in the farm, the built device alerts the farmer with a buzzer. Thus, the suggested solution uses the Internet of Things (IoT) to illuminate the irrigation system, resolving existing farming challenges such as reduced manpower, water waste, and updating the farmer on the live condition of the field on a mobile screen. The thesis should be expanded to diagnose plant disease, seed fraud, and the use of technology techniques.

\section{REFERENCES}

[1]. International Research Journal of Engineering and Technology (IRJET) July 2020

[2]. Smart Farming using IoT, a solution for optimally monitoring farming conditions by Jash Doshi Tirthkumar Patel Santosh kumar Bharti.

[3]. "ESP8266 Overview". Espressif Systems. Retrieved 2017-10-02.

[4]. Brian Benchoff (August 26, 2014). "New Chip Alert: The ESP8266 Wi-Fi Module (It's \$5)". Hackaday. Retrieved 2015-06-24.

[5]. Brian Benchoff (September 6, 2014). "The Current State of ESP8266 Development". Hackaday. Retrieved 2015- 06-24.

[6]. Baker, N. ZigBee and Bluetooth - Strengths and weaknesses for industrial applications. Compute. Control. Eng. 2005, 16, 20-25.

[7]. Dr. V. Vidya Devi, G. Meena Kumari, "RealTime Automation and Monitoring System for Modernized Agriculture", International Journal of Review and Research in Applied Sciences and Engineering (IJRRASE) Vol3 No.1. PP 7-12, 2013.

[8]. Murthy A.S.R., Sudheer Y., Mounika K., Rao K.S., Prasad P.D. Cloud Technology on Agriculture using Sensors. Indian J. Sci. Technol. 2016;9 doi: 10.17485/ijst/2016/v9i17/93103.

[9]. Geng L., Dong T. An agricultural monitoring system based on wireless sensor and depth learning algorithm. Int. J. Online Eng. 2017; 13:127-137. doi: 10.3991/ijoe. v13i12.7885. 
[10]. Hong L.S., Sa Z.S., Yan J. Environment Factors Monitoring System Based on CAN bus. Int. J. Online Eng. 2016; 12:9. doi: 10.3991/ijoe. v12i05.5722.

[11]. Boonchieng E., Chieochan O., Saokaew A. Smart Farm: Applying the Use of NodeMCU, IOT, NETPIE and LINE API for a Lingzhi Mushroom Farm in Thailand. IEICE Trans. Commun. 2018; E101.B:16-23. doi: 10.1587/transcom.2017ITI0002.

[12]. Erazo-Rodas M., Sandoval-Moreno M., Muñoz-Romero S., Huerta M., Rivas-Lalaleo D., Naranjo C., Rojo- Álvarez J. Multiparametric Monitoring in Equatorian Tomato Greenhouses (I): Wireless Sensor Network Benchmarking. Sensors. 2018; 18:2555. doi: 10.3390/s18082555.

[13]. Jagannathan, S, and R. Priyatharshini. "Smart Farming System using Sensors for Agricultural Task Automation." Technological Innovation in ICT for Agriculture and Rural Development (TIAR), IEEE, 2015.

[14]. Dr. J. Jegathesh Amalraj, S. Banumathi and J. Jereena John, - IOT Sensors and Applications: A Surveyll, International Journal of Scientific \& Technology Research, Volume 8, Issue 08, Pages: 998-1003, 2019.

[15]. V.Ramachandran, R. Ramalakshmi,and Seshadhri Srinivasan, An Automated Irrigation System for Smart Agriculture Using the Internet of Things,2018 15th International Conference on Control, Automation, Robotics and Vision (ICARCV) Singapore, November 18-21,2018.

[16]. Mohanraj I, Kirthika Ashokumar, Naren J, Field Monitoring and Automation using IOT in Agriculture Domain,6th International Conference On Advances in Computing Communications, ICACC2016,6-8 September 2016, Cochin, India.
[17]. I.F. Akyildiz, W. Su, Y. Sankarasubramaniam, E. Cayirci, "A survey on sensor networks" in IEEE Communications Magazine.

[18]. Gayatri Londhe et al., "Automated Irrigation System by Using ARM Processor", IJSRET 2014.

\section{Cite this article as :}

Raja Venkatesh Gurugubelli, Dilleswararao Nettimi, Vidya Sagar Gorle, Sairam Panda, Anil Kumar Navuluri, Rosepreet Kaur Bhogal, "Internet of Things Based Smart Agricultural System for Farmers", International Journal of Scientific Research in Computer Science, Engineering and Information Technology (IJSRCSEIT), ISSN : 24563307, Volume 7, Issue 3, pp.535-540, May-June-2021. Available at doi : https://doi.org/10.32628/CSEIT2172142 Journal URL : https://ijsrcseit.com/CSEIT2172142 